gives an expected departure greater than the maximum possible. Detailed calculation would be difficult; but one would anticipate that the maximum deviation expected in $N$ years would bear a constant ratio to the maximum possible deviation, that is, $c \sigma N$, where $c$ is a constant less than $0 \cdot 4$. Now the accumulated departures in Plate XII only appear to fit in with the $\sqrt{ } N$ law because of one very aberrant figure for 400 years ; all the remaining points are fitted much more accurately by the curve given by $R / \sigma=0.2 \mathrm{~N}$. In a series of a hundred observations, this gives an accumulated departure 20 per cent greater than that estimated by the authors, and their "Century storage" reduces to 80 -year storage. This is not actually a very serious matter, as the uncertainties of some of the other figures are probably equally great, but it might be seized on by opponents.

So great a plan will require a long time to come to fruition-time which includes not only the building of the great dams and digging of channels, but also the many years required to build up the reserves of water. Everything depends ultimately on the rainfall of the upper parts of the Nile Basin; but the existing knowledge of the amount of rain and its long-term variation has many gaps, especially in Abyssinia, which must be filled by the setting up of new rain-gauges, and this is one of the first necessary steps. So far as one who is not an engineer can tell, Dr. Hurst and his colleagues have considered all that has to be done and the order of priority, and this should be of great help in the discussion of ways and means.

C. E. P. Breoks

\section{REDUCTION OF FIRE RISKS IN SHIPS}

$\mathrm{T}$ HE Admiralty Chemical Department, Portsmouth, has been busy of late with research into methods of reducing the fire risk on ships arising from paints and other materials used in them. An interim report recently made available reveals that the investigations have followed three lines ; namely, the development of fire-retardant paints for interior use particularly on metal surfaces, the fireproofing of textiles, and the fireproofing of plywood and soft timber.

Fire-Retardant Paints for Interior Use on Board Ship

Dried paint films on an organic base can be a powerful factor in transmitting fire, as experience during the War showed. Fire can be propagated from one compartment to another by means of the paint film on the bulkhead between them. Certain paint types when raised to a sufficiently high temperature on the side of the bulkhead remote from the actual conflagration-blister and form pockets of inflammable vapours. These vapours arise from the partial decomposition of the organic paint medium in the interior of the paint layer. The blisters finally burst, emitting jets of hot gas which ignite spontaneously and burn vigorously, transmitting the fire to any combustible material within reach.

The method used by the Admiralty for evaluating the fire-retardance of paints to be used in such circumstances is as follows. A steel plate, of standard thickness and 12 in. by 12 in. in area, is painted on one side with a primer/top-coat system in the normal manner, adequate time being allowed for drying. The plate is then heated in the vertical position on the unpainted side, with a gas ring supplied with air and gas under standardized pressure. The plate becomes red-hot in about 30 sec. Heating is continued for one minute, by which time combustion of the paint film has largely ceased. Any signs of flashing or flame-propagation are noted, together with any tendency for the red-hot film to detach itself from the plate. This test differentiated decisively between paints of good and bad fire-retardance. Large-scale trials upon painted plates, $6 \mathrm{ft}$. square, were carried out at the Admiralty Fire Testing Ground, Haslar, and the results established the validity of the laboratory test-procedure.

The tests showed that fire retardance was improved by reducing the proportion of medium so far as was consistent with durability and finish, and that titanium and antimony oxides were particularly effective as pigments in the top coat. The primer used was also important, an aluminium pigmented primer being adjudged to have better fire-retardant properties than a red-lead primer.

A specification for such paints has been prepared which prescribes the type of medium and the minimum proportions of titanium dioxide and antimony oxide to be used, and the correct pigment/medium volume ratio. Fire-resistance and other performance tests are included. Such paint is now in service use, but it has disadvantages, notably its matte surface, and work is at present in hand on the development of a finish of good gloss and adequate fire-retardance.

The experimental conclusion that antimony and titanium oxides are better than the other white pigments tested is interesting, in so far as their behaviour in the heated film must be essentially different; antimony oxide is comparatively volatile and easily reducible on heating with organic matter (such as would be present in the film), and titanium dioxide is particularly inert. Whereas it is admitted that antimony compounds are particularly valuable fire retardants in conjunction with textiles, opinion is divided on the fire-retardant value of antimony oxide in paint; thus an American Report (New York Paint and Varnish Production Club, 1943) on an investigation into fire-retardant paints for steel surfaces says that while in the particular tests reported antimony oxide was useful in preventing flashing in paints of low pigment volume, in paints of high pigment volume (as recommended by the Admiralty) it was the worst of the white pigments examined.

\section{An Inorganic Paint System}

Since a paint based on an organic medium can never be entirely incombustible however high the degree of pigmentation achieved, the investigation of paints based on inorganic media was a logical step in the Admiralty investigations. Among the materials examined was cementiferous paint originally developed to make use of the excellent anti-corrosive effect of zinc on steel surfaces and consisting essentially of a zine oxychloride cement containing a high loading of metallic zinc. Such paint showed great promise as a fire-retardant coating, but in its original form suffered from the following disadvantages : (1) It could not be stored in a ready for use form; it consists of two parts which had to be mixed immediately prior to application. (2) It was highly thixotropic and had poor flow properties. (3) Its colour was a dull grey which could not greatly be improved by the addition of white pigments.

It was found that the first defect could be overeome by the addition of an organic liquid as thinner. Thus 20 per cent by weight of industrial spirit 
enabled the paint to be kept indefinitely in a readyfor-use condition, and improved the film properties.

To obtain suitable decorative colours, it was, however, necessary to use the cementiferous paint only as an undercoat and to apply a top-coat in the desired shade. It was found that a partially hydrolysed silicon ester painted over a cementiferous primer gave a paint system which was quite incombustible with excellent weather-resistant and fireretardant properties. When pigmented with titanium dioxide and barium sulphate the film was hard, matte and white; unfortunately, however, the pigmentation was found to affect the film-forming properties of the silicon ester in a discouraging and inexplicable manner. Whereas the pure medium gave continuous, hard and resistant films, the pigmented films tended to craze and crack on drying, and under the fire test small pieces flew off with considerable violence. Usually the cracking resulted in the under-coat being dragged away from the steel surface, and the whole film became faulty and brittle.

The next step was to consider the old problem of plasticizing the silicon ester paint, and di-butyl phthalate was the most satisfactory material. The films, although matte, did not craze or crack on drying or weathering and had excellent fire-retardant properties owing to the fact that the volatile dibutyl phthalate evaporated quickly when heat was applied, instead of charring and burning. Linseed oil was not so successful as a plasticizer.

The remaining problem in the use of silicon ester paints in the manner described was that of stability, for silicon ester medium, whether pigmented or not, shows a gradual increase in viscosity from the date of preparation until, after about three or four months, it sets to a hard gel. The common preserving agents, such as colloidal electrolytes, appear to be ineffective in this case, and the problem is one of great complexity.

The Admiralty has, in effect, met the customary stumbling-blocks in the use of silicon ester paints. Possibly some improvement may lie in the use which has recently been reported of stable silicon esters which are hydrolysed by the user just prior to application. It does not seem unreasonable to suppose that entirely adequate plasticizers for silicon ester will be found in the silicone field.

\section{Fireproofing of Textiles}

It was necessary that attention should be paid to the reduction of the inflammability of the many textile fabrics to be found on board ship.

A water-resistant fireproofing treatment is essential for materials such as ships awnings, boat covers, etc., which are exposed to the weather, and is preferable for materials such as curtains which need to be laundered. Nevertheless a certain amount of fireproofing was carried out on ships by impregnation with water-soluble materials, borax-boric acid mixtures being preferred; reproofing after washing is necessary.

'There is no simple method of producing an adequate water-resistant fireproofing treatment by deposition of insoluble inorganic materials in the fibres. Some metallic oxides, for example, iron and tin, which provide efficient flame-resistance when so deposited, unfortunately induce considerable after-glow.

In the Admiralty work the best results were achieved by impregnation with antimony oxide in conjunction with a chlorinated organic compound such as chlorinated paraffin or polyvinyl chloride co-polymer. The after-glow usually associated with such processes was reduced by the incorporation of zine oxide or stannic phosphate to provide a fire-, water- and weather-resistant process suitable for application to cotton fibres and flax canvases. Large-scale trials demonstrated that the treated fabrics retained a fair degree of flexibility and were very nearly glowproof.

Owing to the somewhat copious evolution of smoke on ignition, it was found that the application of the process on fabries normally situated between decks was restricted; but for canvas gear, for example, weather screens, etc., more or less permanently fitted on the weather deck, the process was strongly recommended.

In addition to the use of fire-proofing processes, attention was paid to the use of less inflammable textile materials. For example, consideration was given to the replacement of cotton by wool, nylon or alginate according to the circumstances. Glass-fibre fabrics proved insufficiently durable under sea-going conditions.

The report under review, taken with other information, shows that the war years have brought antimony oxide, previously neglected, to the forefront as a constituent of fire-proofing compositions on textiles. Antimony oxide, while of itself having only moderate fireproofing properties (it is not completely inert as suggested by the Admiralty report under notice), has greatly enhanced fireproofing properties in the presence of chlorinated organic compounds (usually attributed to the formation of antimony oxychloride), and also other materials such as iron oxide; and it is as a result of these discoveries that its use has been advanced.

\section{Rapid Methods for Fireproofing Plywood and Soft Timber}

In May 1944, work was commenced to devise an efficient method of fire-proofing small wooden articles such as, for example, plywood used in the construction of cases for radio equipment.

The standard method of fire-proofing wood in bulk by impregnation with mono-ammonium phosphate solution was found not to be very suitable owing to the relative slowness with which aqueous solutions are absorbed by wood; and moreover, in the case of plywood, the use of aqueous solutions would cause distortion through attack on the adhesives. This directed attention towards a fire-proofing agent which should be soluble in organic solvents, and in turn led to an examination of the suitability of organic phosphates for the purpose in view. Examination of a large range of materials showed that urea phosphate, which is readily soluble in alcohol, possessed good fire-proofing properties; and an alcoholic solution with a small proportion of wetting agent added was found to give the desired speed of impregnation.

The most satisfactory procedure involved simple immersion of the article to be treated in a hot solution (of 20-30 per cent strength by weight) of urea phosphate in industrial methylated spirits for approximately one hour. The excess was then allowed to drain off, and the article left to dry. Alternatively, though less satisfactorily, in cases where immersion is impracticable, a series of brush applications can be substituted. Large-scale trials at the Admiralty Fire Testing Ground, Haslar, confirmed the efficiency of the process, which has been patented and assigned to the Admiralty.
L. A. JORDAN 